\title{
Multitalent und Aussenseiter
}

Erhard Taverna

\section{Die medizinischen Fakultäten behinderten den}

\section{Autodidakten, wo immer sie konnten.}

Unternehmerfamilie erzählt wird. Die Jugendstilvilla steht in einem Park am Rande des ehemaligen Fabrikgeländes und vereinigt als Institut eine Kinemathek, ein Dokumentationszentrum, einen Filmkonservierungsraum und eine Gedenkstätte. Zahlreiche Filmausschnitte, interaktive Schaukästen und Exponate illustrieren die Meisterleistungen der Lumières, unter denen die Farbfotografie «Autochrome» einen weiteren Höhepunkt markiert. Vor allem Louis erfindet unentwegt weiter: einen Grammophon-Lautsprecher, Fotoapparate und Projektoren, Riesenleinwände, ein Rundum-Diorama und in den 1930ern eine erste Kamera mit Brille für Relief-Aufnahmen.

Trotz unterschiedlicher Interessen bleiben Auguste (1862-1954) und Louis (1864-1948) beruflich und privat ein unzertrennliches Paar. Als visionäre Erfinder, Unternehmer und hervorragende Organisatoren gründen sie eine kommerziell erfolgreiche Gesellschaft, die mit zahlreichen Patenten und eigens ausgebildeten Filmoperateuren internationale Geschäfte tätigt. Das gewonnene Vermögen erlaubt es Auguste, ausschliesslich seinen chemischen und medizinischen Interessen nachzugehen. Aus fotografischen Chemikalien entwickelt er ein Haarfärbemittel, das heute noch ein Bestandteil von Kosmetika ist. Er produziert Röntgenfilme und betreibt bei Ausbruch des Ersten Weltkrieges, auf eigene Kosten, einen radiologischen Dienst für das Spital Hôtel-Dieu.

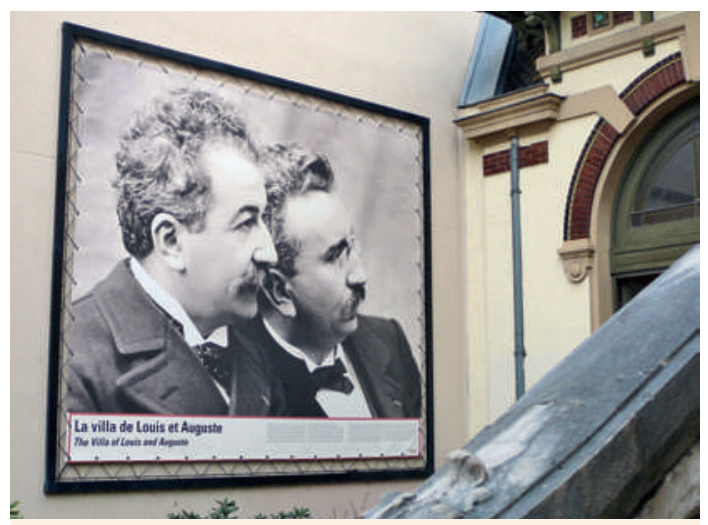

Die visionären Erfinder Auguste und Louis Lumière waren beruflich und privat ein ebenso unzertrennliches wie erfolgreiches Paar.

Auf gemeinsamen Visiten mit dem chirurgischen Chefarzt studiert er die zahlreichen Tetanusfälle, deren Behandlung ihm übertragen wird. Mit verbesserten, intravenösen Techniken, neuartigen Wundverbänden und mehrfach erprobten, diagnostischen Fähigkeiten überzeugt er auch Koryphäen, die dem Aussenseiter und Nicht-Mediziner misstrauisch begegnen. Die Familien beider Brüder engagierten sich gemeinsam in der Behandlung und Pflege der Kriegsverwundeten. 1925 wird Auguste wissenschaftlicher Leiter des Lyoner Spitals Bon-Abri. Er entwickelt Medikamente und vertreibt sie über ein eigenes Dispensaire. Er baut eine pharmazeutische Bibliothek auf, betreibt ein experimentelles Labor in Zusammenarbeit mit Internisten und Chirurgen, er wendet neue Therapien an und wird mit dem Kreuz der Ehrenlegion ausgezeichnet. Die Firma Lumière veröffentlicht ein Fachblatt L'Avenir médical mit einer Beilage Le Foyer médical. Auguste publiziert medizinische Beiträge, unter anderem zur Asthmatherapie. Fünfzehn Forscher kümmern sich um die Chemie, Physik, Histologie, Serologie und Laboranalytik, weitere hundertfünfzig Angestellte bemühen sich um die Produktion und den Vertrieb der eigenen Patente. Die medizinischen Fakultäten behindern den Autodidakten, wo immer sie können. Der Umtriebige exponiert sich, er bietet willkommene Angriffsflächen, etwa wenn er die infektiöse Ätiologie der Tuberkulose bezweifelt oder Krankheiten mit seiner umfassenden Kolloidtheorie erklären will. 1923 versucht die Medizinische Akademie das Anbringen einer Erinnerungstafel in Paris zu verhindern. Sie bevorzugt den Mediziner und Erforscher der Bewegungsabläufe von Mensch und Tier, Etienne-Jules Marey. Denn der Erfinder der «Chronophotographie» entstammt der eigenen Zunft. Die aus Missgunst entfachte Polemik 
gilt natürlich Auguste. Sie findet ein gutes Ende, indem allen Pionieren die verdiente Ehrung zuteil wird.

Den politischen Wirren des 20. Jahrhunderts sind die Brüder Lumière nicht immer gewachsen. Wie die Mehrheit der Franzosen werden sie, nach der Besetzung des Landes, Anhänger von Pétain. Dafür spielt ein Sohn des Älteren eine aktive Rolle in der Résistance. Die in den 1990ern geplante Einführung einer 200-Francs-Note mit dem Brüderporträt stösst auf Kritik. Das Geld wird vor der Auslieferung eingestampft. Doch die Gegenwart profitiert immer noch vom Erbe. Eine Fabrik der 1920er Jahre lieferte den neuen Machthabern im Kreml das Material für bolschewistische Propagandafilme. Bis heute ist die französische Filmindustrie stolz auf diese besondere Beziehung, die ihr während des kalten Krieges, ohne amerikanische Konkurrenz, ein einträgliches Monopol bescherte. 2012 eroberten die Franzosen den 2. Platz unter den ausländischen Filmen. Mit «Asterix und Obelix» an der Spitze haben über sechs Millionen Russinnen und Russen ein Ticket von Lumières Nachkommen gekauft.

* Institut Lumière, 25, rue du Premier-Film, Lyon, www.institut-lumière.org

Weitere Informationen:

- Faucheux M. Auguste et Louis Lumière. Paris: Edition Gallimard; 2011.

- Les Echos, décembre 2012: «La percée du cinéma français à l'étranger». 